\title{
High-speed growth of Si single bulk crystals by expanding low-temperature region in Si melt using noncontact crucible method
}

\author{
Kazuo Nakajima $^{1}$, Kohei Morishita ${ }^{2}$, Ryota Murai $^{1}$
}

1. FUTURE-PV Innovation, Machiikedai 2-2-9, Koriyama, Fukushima 963-0215, Japan

2. Graduate School of Energy Science, Kyoto University, Yoshida, Sakyo-ku, Kyoto 606-8501, Japan

\begin{abstract}
We propose a high speed growth based on noncontact crucible method for obtaining large ingots with a constant diameter. In this method, the Si melt used has a large low-temperature region in its central upper part to ensure Si crystal growth inside it. Therefore, this method has the possibility of attaining a high growth rate using a high cooling rate because the growth rate is determined by the rate of expansion of the low-temperature region in the Si melt. The horizontal and vertical growth rates in $\mathrm{Si}$ melts were experimentally determined. At a cooling rate of $0.4 \mathrm{~K} / \mathrm{min}$, the horizontal growth rate reached $1.5 \mathrm{~mm} / \mathrm{min}$ in the $<110>$ direction and $1.9 \mathrm{~mm} / \mathrm{min}$ in the $<100>$ direction. These growth rates are higher than that of the cast method. The growth rate increased with the cooling rate. The vertical growth rate was determined to be $0.3 \quad 0.6$ $\mathrm{mm} / \mathrm{min}$, and it tended to increase with increasing depth of the Si melt. The diameter of an ingot remained constant during pulling due to a high cooling rate of $0.4 \mathrm{~K} / \mathrm{min}$ because the horizontal growth rate increased as the cooling rate increased and the melt temperature markedly decreased. An ingot with a constant diameter of $21 \mathrm{~cm}$ and a height of $7 \mathrm{~cm}$ was obtained inside a Si melt by the high speed growth using a crucible with $33 \mathrm{~cm}$ diameter.
\end{abstract}

Keywords: A1. Crystal structure; A1. Defects; A2. Growth from melt; A2. Natural crystal growth; A2. Seed growth; B1. Semiconducting silicon; B3. Solar cells PACS codes: $\quad$ 61.72.Mm, 61.72.uf, 61.72.Ff, 81.05.Cy, 81.10.Fq, 81.40.Lm, 85.60.-q

* Corresponding author. Tel.: +81 757539107

E-mail address: nakasisc@energy.kyoto-u.ac.jp (K. Nakajima) 


\section{Introduction}

We previously proposed the noncontact crucible method for reducing stress in $\mathrm{Si}$ bulk crystals and obtaining a crystal diameter as large as the crucible-diameter [ 1 5]. In this method, the Si melt has a large low-temperature region in its upper central part to allow Si crystal growth inside the melt. Nucleation occurs on the surface of the Si melt using a seed crystal, and a crystal grows inside the melt without contact with the crucible wall. The crystal continues to grow while being slowly pulled upward to ensure that the crystal growth remains in the low-temperature region. The growth rate of this method has been considered to be as low as that of the cast method because crystals grow inside crucibles in both methods. This method is similar to the Kyropoulos method, in which crystals are mainly grown by the removal of heat from a Si melt through a seed holder; this method has mainly been used for the growth of oxide crystals such as sapphire [6, 7]. Ravishankar attempted to grow Si ingots using the Kyropoulos method, but the growing ingots came in contact with the crucible wall because a low-temperature region was not clearly established in the Si melt [8]. The definition of the Kyropoulos method in a broad sense is generally used as a growth method to grow crystals inside a melt. The noncontact crucible method is defined as a growth method to intentionally establish a clear low-temperature region in a $\mathrm{Si}$ melt. The clear low-temperature region is effectively used to avoid contacting a crystal with the crucible wall and nucleating from the crucible wall. The clear low-temperature region is especially required for the growth of a $\mathrm{Si}$ crystal inside the Si melt. Therefore, the present method belongs to the Kyropoulos method in a broad sense.

The noncontact crucible method has the following merits compared with the conventional growth methods owing to the presence of the large low-temperature region and growth inside the low-temperature region in the Si melt [9]. The growth interface of an ingot is convex in the growth direction [3]. Because of this, dislocations in the ingot move to the periphery of the ingot from its center during crystal growth. As a result, the dislocation density has been reduced to the order of $10^{2} 10^{3} / \mathrm{cm}^{2}$ by support of a necking technique $[3,4]$. Also, ingots with a crystal diameter as large as the crucible diameter can be grown because the crystal diameter is determined by the size of the low-temperature region in the Si melt [3]. Si single bulk crystals with a diameter as large as $8090 \%$ of the crucible diameter have been obtained. Large ingots are expected to be grown even using small crucibles $\left[\begin{array}{ll}1 & 3\end{array}\right]$. Si single bulk crystals with a square-like shape can be grown using the present method. Perfect square Si single bulk crystals with a long side-face width have also obtained [4]. 
In particular, this method has the possibility of attaining a high growth rate using a high cooling rate even though crystals grow inside crucibles similarly to in the cast method [10 13]. The growth rate of the Czochralski (CZ) method is determined by the pulling rate of an ingot above the surface of a Si melt [14 16]. The horizontal and vertical growth rates of the present method are determined by the rate of expansion of the low-temperature region in a Si melt, as shown in Fig. 1, which is mainly determined by the cooling rate of the Si melt. However, the growth rate for the present method is unclear and may be as low as that of the cast method. Therefore, it is very important to determine the growth rate that can be attained by increasing the cooling rate. It is also very important to determine whether or not the growth rate can exceed that of the cast method. Especially, a high speed growth for obtaining large ingots with a constant diameter will be required to expand the present method for practical use. Therefore, the cooling rate required to obtain such large ingots should be determined.

In this work, we proposed a high speed growth for obtaining large ingots with a constant diameter using the noncontact crucible method. We determined the surface or horizontal growth rates in the $<110>$ and $<100>$ directions inside Si melts for cooling rates of $0.2,0.3$ and $0.4 \mathrm{~K} / \mathrm{min}$. The relationship between the growth rate in the $<110>$ or $<100>$ direction and the cooling rate was experimentally determined. The relationship between the growth length and the initial temperature reduction, $\Delta T_{\text {in }}(\mathrm{K})$, was also determined for several cooling rates. The initial temperature reduction is defined as the difference between the starting temperature, at which the initial crystal was first observed to grow from the seed crystal, and the final temperature, at which the pulling growth was started. Using these results, a Si single bulk crystal with a constant diameter of $21 \mathrm{~cm}$ and a height of $7 \mathrm{~cm}$ was grown with high speed growth using a

small crucible with $33 \mathrm{~cm}$ diameter. Wafers with dimensions of $15.615 .6 \mathrm{~cm}^{2}$ were obtained from the ingot.

\section{Experiments}

Using the noncontact crucible method, $\mathrm{Si}$ ingots were grown utilizing silica crucibles of 28, 30 and $33 \mathrm{~cm}$ diameter. The inner wall of the crucible was not coated with $\mathrm{Si}_{3} \mathrm{~N}_{4}$ particles. High-purity $\mathrm{Si}$ feedstock (more than $9 \mathrm{~N}$ ) was placed together with P-doped n-type Si feedstock in the crucible. The thickness of the Si melt was 3.0, 4.0 or $5.0 \mathrm{~cm}$. The amount of Si feedstock used for the growth of the Si ingots was $7.26 \mathrm{~kg}$ for crucibles $28 \mathrm{~cm}$ in diameter, $8.34 \mathrm{~kg}$ for crucibles $30 \mathrm{~cm}$ in diameter and $10.10 \mathrm{~kg}$ for crucibles $33 \mathrm{~cm}$ in diameter when the thickness of the Si melt was $5.0 \mathrm{~cm}$. The feedstock was completely melted by heating in a furnace to temperatures of above 
$1450{ }^{\circ} \mathrm{C}$ in an argon atmosphere. The argon pressure was set to slightly below $0.1 \mathrm{MPa}$ in the present study. After heating, a Si seed crystal was dipped into the Si melt, and a necking technique was used for seed growth $[17,18]$. The melt was then cooled to control the initial size of the ingot in the low-temperature region. The seed crystal was a $\mathrm{Si}$ single crystal obtained from ingots grown using the CZ method [14-16]. The orientation and diameter of the seed crystal were (100) and $1.2 \mathrm{~cm}$, respectively. The total temperature reduction, $\Delta T_{t}(\mathrm{~K})$, required to obtain ingots of an appropriate size was between 30 and $74.6 \mathrm{~K}$. The total temperature reduction is defined as the difference between the starting temperature, at which the initial crystal was first observed to start growing from the seed crystal, and the final temperature, at which the crystal growth was finished. $\mathrm{A} \Delta T_{\text {in }}(\mathrm{K})$ of $30 \mathrm{~K}$ was used to induce expansion of the crystal along the surface of the Si melt. The starting temperature was determined by directly observing the melt surface near the seed. The temperature reduction was read from a monitor on the heater system. The temperature reduction measured at the heater system does not always exactly correspond to the real amount of supercooling used for Si crystal growth because of thermal inertia in the Si melt. However, it can be used as an indicator to relatively compare each temperature reduction among the present growth of ingots, and we can know the approximate amount of the real temperature reduction from the temperature reduction measured at the heater system. The cooling rate was $0.2,0.3$ or $0.4 \mathrm{~K} / \mathrm{min}$. The crystals were then allowed to continue growing while they were slowly pulled upward at a constant rate of $0.2,0.3$ or $0.4 \mathrm{~mm} / \mathrm{min}$ without the use of a load cell. Each crystal was continuously rotated at a rate of $0.8 \mathrm{rpm}$, and the crucible was continuously rotated at a rate of $0.4 \mathrm{rpm}$ during the ingot growth. The different co-rotating speeds were used to know the contact of the grown crystal with the crucible wall by the first swing of the crystal when the clear low-temperature could not be established in the Si melt.

\section{Results}

\subsection{Horizontal growth rate of Si single bulk crystals in the $<110>$ and $<100>$ directions}

To determine the surface or horizontal growth rates of Si single bulk crystals, n-type ingots were prepared using silica crucibles without a $\mathrm{Si}_{3} \mathrm{~N}_{4}$ coating. The growth length on the top surface of the ingots was determined by making marks in it. Fig. 2 (a) shows an n-type ingot with a size of $20.320 .3 \mathrm{~cm}^{2}$, a diagonal length of $25.0 \mathrm{~cm}$, a mass of $2960 \mathrm{~g}$ (solidification ratio: $41 \%$ ) and a thickness of $4.0 \mathrm{~cm}$. The ingot was grown using a crucible with $28 \mathrm{~cm}$ diameter. The thickness of the Si melt was $5.0 \mathrm{~cm}$ 
and the cooling rate was $0.3 \mathrm{~K} / \mathrm{min}$. Both $\Delta T_{\text {in }}$ and $\Delta T_{t}$ were $30 \mathrm{~K}$, which means that the melt temperature remained constant without cooling when the ingot was pulled upward after the crystal expanded along the surface of the melt. The growth process of this ingot is shown in Fig. 2 (b). After the necking process, the ingot was grown during the cooling of the melt by $\Delta T_{\text {in }}=30 \mathrm{~K}$ without pulling. The ingot was pulled upward by $0.3,0.4,0.4$ and $0.2 \mathrm{~cm}$ at $\Delta T_{\text {in }}=17,22,27$ and $30 \mathrm{~K}$ with a pulling rate of $2 \mathrm{~mm} / \mathrm{min}$ for the purpose of making marks to determine the growth rate, respectively. The top surface of the ingot had four steps, which were located at distances of 5.2, 6.8, 9.0 and $10.0 \mathrm{~cm}$ in the $<110>$ direction and at distances of $7.1,8.0,11.6$ and $12.3 \mathrm{~cm}$ in the $<100>$ direction from the center of the seed. The growth times for these growth lengths were 57, 73, 90 and $100 \mathrm{~min}$, respectively. At $\Delta T_{\text {in }}=30 \mathrm{~K}$, the ingot was continuously pulled upward with a pulling rate of $0.4 \mathrm{~mm} / \mathrm{min}$ without cooling the melt. The ingot had a square-like shape because the growth rate in the $<100>$ direction was larger than that in the $<110>$ direction. Figs. 2 (c) and (d) show the top surface of the ingot in the $<110>$ and $<100>$ directions, respectively. The top surface has four steps corresponding to the growth process shown in Fig. 2 (b). The side face in the $<110>$ direction was flat but the $<100>$ corner had a fan-shaped face [4]. The side-face widths were 10.3 and $10.7 \mathrm{~cm}$ for this ingot, which corresponded to the step at $\Delta T_{\text {in }}=17$ K shown in Fig. 2 (d).

The growth rate was determined from the growth length and growth time. Fig. 3 shows the growth length as a function of the growth time in the $<110>$ direction. The cooling rates were $0.2,0.3$ and $0.4 \mathrm{~K} / \mathrm{min}$. The growth length almost linearly increased with the growth time, and the growth rate, given by the slope, increased with the cooling rate. From these results, the growth rate was determined to be 0.6, 1.0 and $1.5 \mathrm{~mm} / \mathrm{min}$ for the cooling rates of $0.2,0.3$ and $0.4 \mathrm{~K} / \mathrm{min}$, respectively. Fig. 4 shows the growth length as a function of the growth time in the $<100>$ direction. The cooling rates were $0.2,0.3$ and $0.4 \mathrm{~K} / \mathrm{min}$. The growth length almost linearly increased with the growth time. The growth rate was determined to be $0.8,1.3$ and $1.9 \mathrm{~mm} / \mathrm{min}$ for the cooling rates of $0.2,0.3$ and $0.4 \mathrm{~K} / \mathrm{min}$, respectively. The growth rate in the $<100>$ direction was about 1.3 times higher than that in the $<110>$ direction. However, the growth rate in the $<100>$ direction was not $\sqrt{2}$ times higher than that in the $<110>$ direction because the $<100>$ corners had circular fan-shaped faces as shown in Fig. 2 (d). In this work, the linear fits were used to determine the initial growth rates in each direction. At the cooling rate of $0.4 \mathrm{~K} / \mathrm{min}$, the five data points were on the linearly fitted line in Fig. 3 and the lower four data points except for the upper one were almost on the linearly fitted line in Fig. 4 because the $<100>$ corners had circular fan-shaped 
faces at the final stage of the growth as shown in Fig. 2 (d).

The horizontal growth rates in the $<110>$ and $<100>$ directions increased with the cooling rate. The horizontal growth rates at the cooling rate of $0.4 \mathrm{~K} / \mathrm{min}$ were more than twice those at the cooling rate of $0.2 \mathrm{~K} / \mathrm{min}$. A high growth rate of about 2 $\mathrm{mm} / \mathrm{min}$ was obtained in the $<100>$ direction for the cooling rate of $0.4 \mathrm{~K} / \mathrm{min}$. This growth rate is much higher than that of the cast method and is as high as that of the $\mathrm{CZ}$ method. The relationship between the growth length and $\Delta T_{\text {in }}$ was determined in the $<110>$ direction for the cooling rates of $0.2,0.3$ and $0.4 \mathrm{~K} / \mathrm{min}$ as shown in Fig. 5. The growth length almost linearly depended on $\Delta T_{\text {in }}$ regardless of the cooling rate, i.e., the growth length was simply determined by only $\Delta T_{i n}$. Therefore, we can use a higher cooling rate to obtain the same size of ingot and reduce the growth time.

The vertical growth rate is very important because it determines the maximum rate at which ingots can be pulled above the surface of Si melts, i.e., the actual growth rate of ingots. During the growth of a crystal along the surface of a Si melt, the crystal also grew inside the melt in the vertical direction. Just when the ingot came in contact with the bottom of the crucible, the ingot swung in the melt, which could be observed through the windows of the furnace chamber. The vertical growth rate was determined by direct observation of the first swing of the ingots at the initial stage of growth, and it was estimated from the depth of the melt and the time between the start time of the surface growth from the seed crystal and the time at which the ingot swung. Fig. 6 shows the vertical growth rate as a function of the depth of the $\mathrm{Si}$ melt used for the growth of the ingots when the cooling rate was $0.2 \mathrm{~K} / \mathrm{min}$. The exact growth direction was not known, but it was approximately in the $<100>$ direction. The vertical growth rate tended to increase with the depth of the Si melt even though the data were scattered, and it was determined to be $0.3 \quad 0.6 \mathrm{~mm} / \mathrm{min}$. The vertical growth rate was not particularly large because the depths of the Si melts used in this work were limited to below $5 \mathrm{~cm}$ and the cooling rate was only $0.2 \mathrm{~K} / \mathrm{min}$.

\subsection{Size and shape of single bulk crystals grown using high cooling rate}

Ingots were usually grown using a cooling rate of $0.2 \mathrm{~K} / \mathrm{min}$ in the previous study. In this case, the horizontal growth rates were 0.6 and $0.8 \mathrm{~mm} / \mathrm{min}$ in the $<110>$ and $<100>$ directions, respectively. For such low horizontal growth rates, it was difficult to maintain a constant ingot diameter during crystal growth. The shape and size of ingots grown with a high cooling rate of $0.4 \mathrm{~K} / \mathrm{min}$ were investigated. Fig. 7 (a) shows an

n-type ingot with a size of $23.5 \quad 23.5 \mathrm{~cm}^{2}$, a diagonal length of $24.5 \mathrm{~cm}$, a mass of $4520 \mathrm{~g}$ (solidification ratio: $54 \%$ ) and a thickness of $5.5 \mathrm{~cm}$. The ingot was grown using 
a crucible with $30 \mathrm{~cm}$ diameter and a $\mathrm{Si}$ melt depth of $5 \mathrm{~cm}$. After the necking process, the ingot was grown while cooling the melt by $\Delta T_{i n}=30 \mathrm{~K}$ without pulling. During the growth of the crystal along the surface of the melt, the ingot was occasionally and rapidly pulled upward by $0.3 \mathrm{~cm}$ at $\Delta T_{\text {in }}=15,20,25$ and $30 \mathrm{~K}$ with a pulling rate of 2 $\mathrm{mm} / \mathrm{min}$ for the purpose of making marks to determine the growth rate as shown in Figs. 3 and 4 . The top surface of the ingot had four steps which were located at distances of $5.4,7.1,8.8$ and $10.1 \mathrm{~cm}$ in the $<110>$ direction and at distances of 7.1, 9.1, 10.2 and $11.2 \mathrm{~cm}$ in the $<100>$ direction from the center of the seed crystal. The growth times for these growth lengths were 34, 46, 59 and $72 \mathrm{~min}$, respectively. At $\Delta T_{\text {in }}=30 \mathrm{~K}$, the ingot was grown while being continuously pulled upward with a pulling rate of $0.4 \mathrm{~mm} / \mathrm{min}$ and the melt cooled by $\Delta T_{t}=31.4 \mathrm{~K}$. The difference between $\Delta T_{\text {in }}$ and $\Delta T$ was only 1.4 $\mathrm{K}$, which means that the melt temperature was almost constant while the ingot was pulled upward after the crystal expanded along the surface of the melt. As shown in Fig. 7 (a), the diameter of the ingot decreased during crystal growth because the melt temperature was almost constant during pulling. The top surface was sufficiently large to obtain a $15.615 .6 \mathrm{~cm}^{2}$ wafer, as shown in Fig. 7 (b), but it was difficult to maintain the initial size of the ingot during crystal growth without cooling. When the lower cooling rate of $0.2 \mathrm{~K} / \mathrm{min}$ was used, the diameter of the ingots was also lower during crystal growth because the horizontal growth rate was lower. Fig. 7 (c) shows an n-type ingot with a top size of $17.0 \quad 17.2 \mathrm{~cm}^{2}$, a diagonal length of $24.3 \mathrm{~cm}$, a mass of $5800 \mathrm{~g}$ (solidification ratio: $57 \%$ ) and a thickness of $7.0 \mathrm{~cm}$. The ingot was grown using a crucible with $33 \mathrm{~cm}$ diameter and a Si melt depth of $5 \mathrm{~cm}$. After the necking process, the ingot was grown while cooling the melt by $\Delta T_{\text {in }}=35 \mathrm{~K}$ without pulling. During the growth of the crystal along the surface of the melt, the ingot was occasionally and rapidly pulled upward by $0.5 \mathrm{~cm}$ at $\Delta T_{\text {in }}=24$ and $35 \mathrm{~K}$ with a pulling rate of $2 \mathrm{~mm} / \mathrm{min}$ for the purpose of making marks. The growth rates were 1.0 and $1.1 \mathrm{~mm} / \mathrm{min}$ in the $<110>$ and $<100>$ directions, respectively. The top surface of the ingot had two steps, which were located at distances of 4.2 and $8.6 \mathrm{~cm}$ in the $\langle 110\rangle$ direction and at distances of 4.1 and $8.2 \mathrm{~cm}$ in the $<100>$ direction from the center of the seed crystal. The growth times for these growth lengths were 53 and $81 \mathrm{~min}$, respectively. At $\Delta T_{\text {in }}=$ $35 \mathrm{~K}$, the ingot was grown while pulling it upward with a pulling rate of $0.4 \mathrm{~mm} / \mathrm{min}$ and the melt cooled by $\Delta T_{t}=74.6 \mathrm{~K}$. The difference between $\Delta T_{\text {in }}$ and $\Delta T_{t}$ was $39.6 \mathrm{~K}$, which means that the melt temperature markedly decreased during the pulling of the ingot after the crystal expanded along the surface of the melt. As shown in Fig. 7 (c), the diameter of the ingot increased during crystal growth because the melt temperature markedly decreased during pulling with a cooling rate of $0.4 \mathrm{~K} / \mathrm{min}$. The top surface had 
not enough size to obtain a $15.6 \quad 15.6 \mathrm{~cm}^{2}$ wafer, as shown in Fig. 7 (d), but it was easy to maintain the initial size of the ingot during crystal growth using the high cooling rate. The center of the ingot was sufficiently large to obtain a $15.6 \quad 15.6 \mathrm{~cm}^{2}$ wafer even when using the crucible with $33 \mathrm{~cm}$ diameter. The top surface of the ingot had a square-like shape but the center of the ingot had a circular shape. It was difficult to maintain the initial square-like shape during crystal growth. The top surface of the ingot did not have a perfect square shape because the corners in the $<100\rangle$ direction on the top surface were circular owing to the small difference between the growth rates in the $<110>$ and $<100>$ directions.

For the practical use of ingots for solar cells, it is important to keep the initial size of the ingot constant during crystal growth. Fig. 8 (a) shows an n-type Si single bulk crystal with a diagonal length of $23 \mathrm{~cm}$, a mass of $6440 \mathrm{~g}$ (solidification ratio: 64\%) and a thickness of $7.0 \mathrm{~cm}$. The ingot was grown using a crucible with $33 \mathrm{~cm}$ diameter, a $\mathrm{Si}$ melt depth of $5 \mathrm{~cm}$ and a cooling rate of $0.4 \mathrm{~K} / \mathrm{min}$. After the necking process, the ingot was grown while cooling the melt by $\Delta T_{\text {in }}=30 \mathrm{~K}$ without pulling. The ingot was rapidly pulled upward by $0.5 \mathrm{~cm}$ at $\Delta T_{\text {in }}=25 \mathrm{~K}$ with a pulling rate of $2 \mathrm{~mm} / \mathrm{min}$ for the purpose of making marks. The growth rates were 1.4 and $1.5 \mathrm{~mm} / \mathrm{min}$ in the $<110>$ and $<100>$ directions, respectively. The top surface of the ingot had a step located at distances of $8.0 \mathrm{~cm}$ in the $<110>$ direction and $8.5 \mathrm{~cm}$ in the $<100>$ direction from the center of the seed crystal. The growth time for these growth lengths was $58 \mathrm{~min}$. At $\Delta T_{\text {in }}=30 \mathrm{~K}$, the ingot was grown while pulling it upward with a pulling rate of $0.4 \mathrm{~mm} / \mathrm{min}$ and the melt cooled by $\Delta T_{t}=68.3 \mathrm{~K}$. The difference between $\Delta T_{\text {in }}$ and $\Delta T_{t}$ was $38.3 \mathrm{~K}$, which means that the melt temperature markedly decreased during the pulling of the ingot after the crystal expanded along the surface of the melt. The ingot was circular because the side-face width was very short $(4.85 .1 \mathrm{~cm}$ ) as shown in Fig. 8 (b). A fan-shaped face appeared in the $<100>$ direction at the point shown by the red arrow; thus, the top surface of the ingot has circular corners in the $<100>$ direction. As shown in Fig. 8 (c), the diameter of the ingot remained constant during pulling with a high cooling rate of $0.4 \mathrm{~K} / \mathrm{min}$ because the horizontal growth rate increased with increasing cooling rate and the melt temperature markedly decreased. The ingot was sufficiently large to obtain a $15.615 .6 \mathrm{~cm}^{2}$ wafer even when using the crucible with $33 \mathrm{~cm}$ diameter. The same diagonal length of the top surface of ingots was obtained for cooling rates between 0.2 and $0.4 \mathrm{~K} / \mathrm{min}$. Therefore, we can use a larger cooling rate to obtain ingots with the same diameter. 


\subsection{Horizontal growth rate of Si multicrystals using the present method}

The growth rate of Si multicrystals was compared with that of single crystals. Fig. 9 shows the growth length of the top surface as a function of the growth time in the $<110>$ direction for a number of crystals. The growth length of the top surface was defined as half the diameter of the top surface of ingots grown with a cooling rate of 0.2 $\mathrm{K} / \mathrm{min}$. After the necking process, the top parts of these ingots were grown during the cooling of the Si melt by $\Delta T_{\text {in }}$ without pulling. $\Delta T_{\text {in }}$ was varied between 15.0 and $43.6 \mathrm{~K}$. The growth length tended to linearly increase with increasing growth time even through the data were scattered. The slope corresponded to the growth rate for the cooling rate of $0.2 \mathrm{~K} / \mathrm{min}$, which was determined to be approximately $0.6 \mathrm{~mm} / \mathrm{min}$ using the linear least squares fit for equally weighted data as shown by (a) line in Fig. 9. However, the growth rate saturated after $150 \mathrm{~min}$ because the crystal diameter approached to the crucible diameter. The expansion of the low-temperature region almost stopped near the crucible wall where the melt temperature was higher than that in the low-temperature region. Therefore, the growth rate was determined to be approximately $0.7 \mathrm{~mm} / \mathrm{min}$ before 150 min as shown by (b) line in Fig. 9.

To more precisely determine the growth rate of Si multicrystals, the growth rate of part of a Si multicrystal was compared with that of part of a single crystal on the top surface of an ingot. Fig. 10 (a) shows an ingot for which half is a multicrystal and half is a single crystal. The diameter, height and mass of this ingot were $24 \mathrm{~cm}, 3.0 \mathrm{~cm}$ and $2100 \mathrm{~g}$, respectively. The multicrystal part was grown using the nucleation sites of particles such as $\mathrm{Si}_{3} \mathrm{~N}_{4}$ or $\mathrm{SiC}$ as contaminants as shown in Fig. 10 (b). The cooling rate of $0.2 \mathrm{~K} / \mathrm{min}$ and $\Delta T_{\text {in }}$ of $28.3 \mathrm{~K}$ were used for this ingot. After the necking process, the top part of the ingot was grown while cooling the Si melt by $\Delta T_{\text {in }}=28.3 \mathrm{~K}$ without pulling. The growth lengths of the multicrystal and single crystal were 11.3 and $10.1 \mathrm{~cm}$ for the growth time of $133 \mathrm{~min}$, respectively. The surface growth rate was determined to be $0.8 \mathrm{~mm} / \mathrm{min}$ for the multicrystal and $0.7 \mathrm{~mm} / \mathrm{min}$ for the single crystal. It was clarified that the growth rate of the multicrystal was slightly higher than that of the single crystal because the multicrystal grew without facet growth.

\section{Discussion}

It is desirable to clarify the maximum growth rate for the present method. The growth rate can be expressed as

$$
\begin{aligned}
V(\mathrm{~cm} / \mathrm{min}) & =\mathrm{d} r / \mathrm{d} t \\
& =\left(\mathrm{d} \Delta T_{\text {in }} / \mathrm{d} t\right) /\left(\mathrm{d} \quad \Delta T_{\text {in }} / \mathrm{d} r\right) .
\end{aligned}
$$




$$
=\left(\mathrm{d} \Delta T_{\text {in }} / \mathrm{d} t\right) / G_{T}^{s} \text {. }
$$

Here, $V(\mathrm{~cm} / \mathrm{min})$ is the growth rate, $\quad r(\mathrm{~cm})$ is the grown length at $\Delta T_{i n}$, and $t(\mathrm{~min})$ is the growth time required to obtain the growth length. $\mathrm{d} \Delta T_{\text {in }} / \mathrm{d} t$ is the cooling rate, which is expressed in terms of the initial temperature reduction, and $\mathrm{d} \Delta T_{\text {in }} / \mathrm{d} r$ is the temperature gradient near the surface of the melt on the growth interface of expanding crystal along the surface of the Si melt, $G_{T}^{s}(\mathrm{~K} / \mathrm{cm})$.

In the present method, the initial temperature reduction was defined as the difference between the starting temperature, at which the initial crystal was first observed to grow from the seed crystal, and the final temperature, at which the pulling growth started. Therefore, the initial temperature reduction is the temperature reduction that was used to induce crystal growth along the surface of the Si melt from the seed crystal. The low-temperature region in the central part of the Si melt became larger across the surface of the Si melt as the initial temperature reduction increased, which resulted in an increase in the temperature difference near the surface of the $\mathrm{Si}$ melt between the center and periphery of the low-temperature region. In the present work, the temperature gradient across the crucible near the surface of the Si melt was almost constant when the low-temperature region was expanding because the side-face width $\left(\begin{array}{ll}10 & 12 \mathrm{~cm}\end{array}\right)$ was almost constant for $\Delta T_{\text {in }}=30 \mathrm{~K}$ regardless the cooling rate. The side-face width, $d(\mathrm{~cm})$, of a square-shaped crystal can be expressed as [4]

$$
\text { d } \Delta T / G_{T}^{s} .
$$

Here, $\Delta T(\mathrm{~K})$ is the supercooling that occurred in the radial direction of the ingots. The result that the side-face width was almost constant at the same $\Delta T_{\text {in }}$ means that $G_{T}{ }^{s}$ was also almost constant regardless of the cooling rate. Therefore, as indicated by Eq. (1), the growth rate is almost proportional to the cooling rate.

The growth rate of the present method increases with the cooling rate. The limit of the cooling rate depends on the heat capacity of the furnace. For the present furnace, the high cooling rate sometimes caused overcooling below the setting temperature. For example, during the surface growth of the ingot shown in Fig. 8 (a), the cooling was occasionally stopped at $\Delta T_{\text {in }}=10,15,20,25$ and $30 \mathrm{~K}$ to prevent the overcooling of the furnace. The control of the overcooling of the furnace was also effective for keeping the initial diameter constant during crystal growth as shown in Fig. 8 (c). Therefore, the diameter of the ingot remained constant during pulling with a high cooling rate of 0.4 $\mathrm{K} / \mathrm{min}$. From these results, this furnace has sufficient heat capacity to increase the 
cooling rate to above $0.4 \mathrm{~K} / \mathrm{min}$, at which the horizontal growth rate will be higher than $2 \mathrm{~mm} / \mathrm{min}$.

In the case that $G_{T}^{s}$ is not constant, the growth rate strongly depends on the temperature gradient in the Si melt as indicated by Eq. (1). When the temperature gradient is larger, it is more difficult to significantly expand the low-temperature region in the Si melt. The growth rate is also lower for a larger temperature gradient in the $\mathrm{Si}$ melt. To obtain ingots with a diameter as large as the crucible diameter, it is better to select a low temperature gradient in the Si melt because a large low-temperature region can be easily obtained.

\section{Conclusions}

The noncontact crucible method was used to prepare Si single bulk crystals with a constant diameter using the high speed growth. The surface or horizontal growth rates in the $<110>$ and $<100>$ directions were determined as functions of the cooling rate. The growth rate increased with the cooling rate. When the cooling rate was $0.4 \mathrm{~K} / \mathrm{min}$, the growth rate reached $1.5 \mathrm{~mm} / \mathrm{min}$ in the $<110>$ direction and $1.9 \mathrm{~mm} / \mathrm{min}$ in the $<100>$ direction. The growth rate of the present method was higher than that of the cast method. A high cooling rate can be used to obtain same size of an ingot as that grown by

a low cooling rate because the growth length did not strongly depend on the cooling rate. The diameter of ingots remained constant during pulling when a larger cooling rate of $0.4 \mathrm{~K} / \mathrm{min}$ was used. We obtained an ingot with a constant diameter of $21 \mathrm{~cm}$ and a height of $7 \mathrm{~cm}$, using a crucible with $33 \mathrm{~cm}$ diameter. Thus, large ingots with a constant diameter can be grown using a high cooling rate because the horizontal growth rate increases with the cooling rate.

\section{Acknowledgements}

This study was supported by Japan Science and Technology Agency (JST) under the Ministry of Education, Culture, Sports, Science and Technology of Japan (MEXT). We would like to thank S. Ochi of Kyoto University, K. Kutsukake of Tohoku University, N. Usami of Nagoya University, and T. Buonassisi of Massachusetts Institute of Technology for their support. 


\section{References}

[1] K. Nakajima, R. Murai, K. Morishita, K. Kutsukake, N. Usami, J. Cryst. Growth 344 (2012) 6.

[2] K. Nakajima, K. Morishita, R. Murai, K. Kutsukake, J. Cryst. Growth 355 (2012) 38.

[3] K. Nakajima, R. Murai, K. Morishita, K. Kutsukake, J. Cryst. Growth 372 (2013) 121.

[4] K. Nakajima, R. Murai, K. Morishita, Jpn. J. Appl. Phys. 53 (2014) 025501-1.

[5] K. Nakajima, K. Morishita, R. Murai, N. Usami, J. Crystal Growth, 389 (2014) 112.

[6] D. F. Bliss, Evolution and application of the Kyropoulos crystal growth method, in: R. S. Feigelson (Ed.), 50 years progress in Crystal Growth: A Reprint Collection, Elsevier, 2004, pp. 29-33.

[7] S. E. Demina, E. N. Bystrova, M. A. Lukanina, V. M. Mamedov, V. S. Yuferev, E. V. Eskov, M. V. Nikolenko, V. S. Postolov, and V. V. Kalaev, Opt. Mater. 30 (2007) 62.

[8]P. S. Ravishankar: Sol. Energy Mater. 12 (1985) 361.

[9] K. Nakajima, R. Murai, K. Morishita, K. Kutsukake, in 39th IEEE Photovoltaic Specialists Conference (39th PVSC), Tampa, Florida, US, June 16-21, 2013.

[10] K. Fujiwara , W. Pan, N. Usami, K. Sawada, M. Tokairin, Y. Nose, A. Nomura, T. Shishido, K. Nakajima, Acta Mater. 54 (2006) 3191.

[11] K. Nakajima, K. Kutsukake, K. Fujiwara, K. Morishita, S. Ono, J. Cryst. Growth 319 (2011) 13.

[12] T. F. Li, H. C. Huang, H. W. Tsai, A. Lan, C. Chuck, C. W. Lan, J. Cryst. Growth 340 (2012) 202.

[13] K. Kutsukake, H. Ise, Y. Tokumoto, Y. Ohno, K. Nakajima, I. Yonenaga, J. Cryst. Growth 352 (2012) 173.

[14] J. Czochralski, Zeitschrift Physikalische Chem. 92 (1917) 219.

[15] S. N. Rea, J. Cryst. Growth 54 (1981) 267.

[16] W. Zulehner, J. Cryst. Growth 65 (1983) 189.

[17] W. C. Dash, J. Appl. Phys. 30 (1959) 459.

[18] X. Huang, T. Taishi, I. Yonenaga, K. Hoshikawa, Jpn. J. Appl. Phys. 40 (2001) 12. 


\section{Figure captions}

Fig. 1 Surface or horizontal and vertical growth rates in a Si melt determined by the rate of expansion of the low-temperature region.

Fig. 2 (a) n-Type ingot with a square-like shape of size $20.3 \quad 20.3 \mathrm{~cm}^{2}$. The top surface has four steps corresponding to the growth process. (b) Growth process of this ingot for the purpose of making marks to determine the growth rate. (c) Top surface of the ingot in the $\langle 110>$ direction. (d) Top surface of the ingot in the $<100>$ direction.

Fig. 3 Surface or horizontal growth length in the $<110>$ direction as a function of the growth time. The growth rate was determined from the slope.

Fig. 4 Surface or horizontal grown length in the $<100>$ direction as a function of the growth time. The growth rate was determined from the slope.

Fig. 5 Relationship between the grown length and $\Delta T_{\text {in }}$ in the $<110>$ direction for cooling rates of $0.2,0.3$ and $0.4 \mathrm{~K} / \mathrm{min}$. The growth length almost linearly depended on $\Delta T_{\text {in }}$ regardless of the cooling rate.

Fig. 6 Vertical growth rate as a function of the depth of the Si melt used for the growth of ingots when the cooling rate was $0.2 \mathrm{~K} / \mathrm{min}$. The solid line was inserted as a linear least squares fit for equally weighted data.

Fig. 7 (a) n-Type ingot with a diameter that decreased during crystal growth because the melt temperature was almost constant during pulling. (b) Top surface sufficiently large to obtain a $15.6 \quad 15.6 \mathrm{~cm}^{2}$ wafer. It was difficult to maintain the initial size of the ingot during crystal growth without cooling. (c) n-Type ingot with a diameter that increased during crystal growth because the melt temperature was markedly decreased during pulling with a cooling rate of $0.4 \mathrm{~K} / \mathrm{min}$. (d) Top surface with a small size not to obtain a $15.6 \quad 15.6 \mathrm{~cm}^{2}$ wafer. The center of the ingot was sufficiently large to obtain a $15.6 \quad 15.6 \mathrm{~cm}^{2}$ wafer at the high cooling rate.

Fig. 8 (a) n-Type ingot with a circular shape. (b) Top surface of the ingot with short side-face widths and fan-shaped faces in the $<100>$ direction. A fan-shaped face appeared at the point shown by the red arrow. (c) Ingot with a diameter that remained constant during pulling with a high cooling rate of $0.4 \mathrm{~K} / \mathrm{min}$ because the horizontal growth rate increased with increasing cooling rate and the melt temperature markedly decreased.

Fig. 9 Surface or horizontal growth length of the top surface of Si multicrystal ingots as a function of the growth time. The growth length of the top surface was defined as half the diameter of the top surface of ingots grown with the cooling rate of 0.2 
$\mathrm{K} / \mathrm{min}$. The growth was determined to be about $0.6 \mathrm{~mm} / \mathrm{min}$ by (a) line and about $0.7 \mathrm{~mm} / \mathrm{min}$ by (b) line before $150 \mathrm{~min}$.

Fig. 10 Ingot for which half is a multicrystal and half is a single crystal. (b) Multicrystal part grown using nucleation sites of particles such as $\mathrm{Si}_{3} \mathrm{~N}_{4}$ or $\mathrm{SiC}$ as contaminants. The surface growth rate was $0.8 \mathrm{~mm} / \mathrm{min}$ for the multicrystal and $0.7 \mathrm{~mm} / \mathrm{min}$ for the single crystal. 


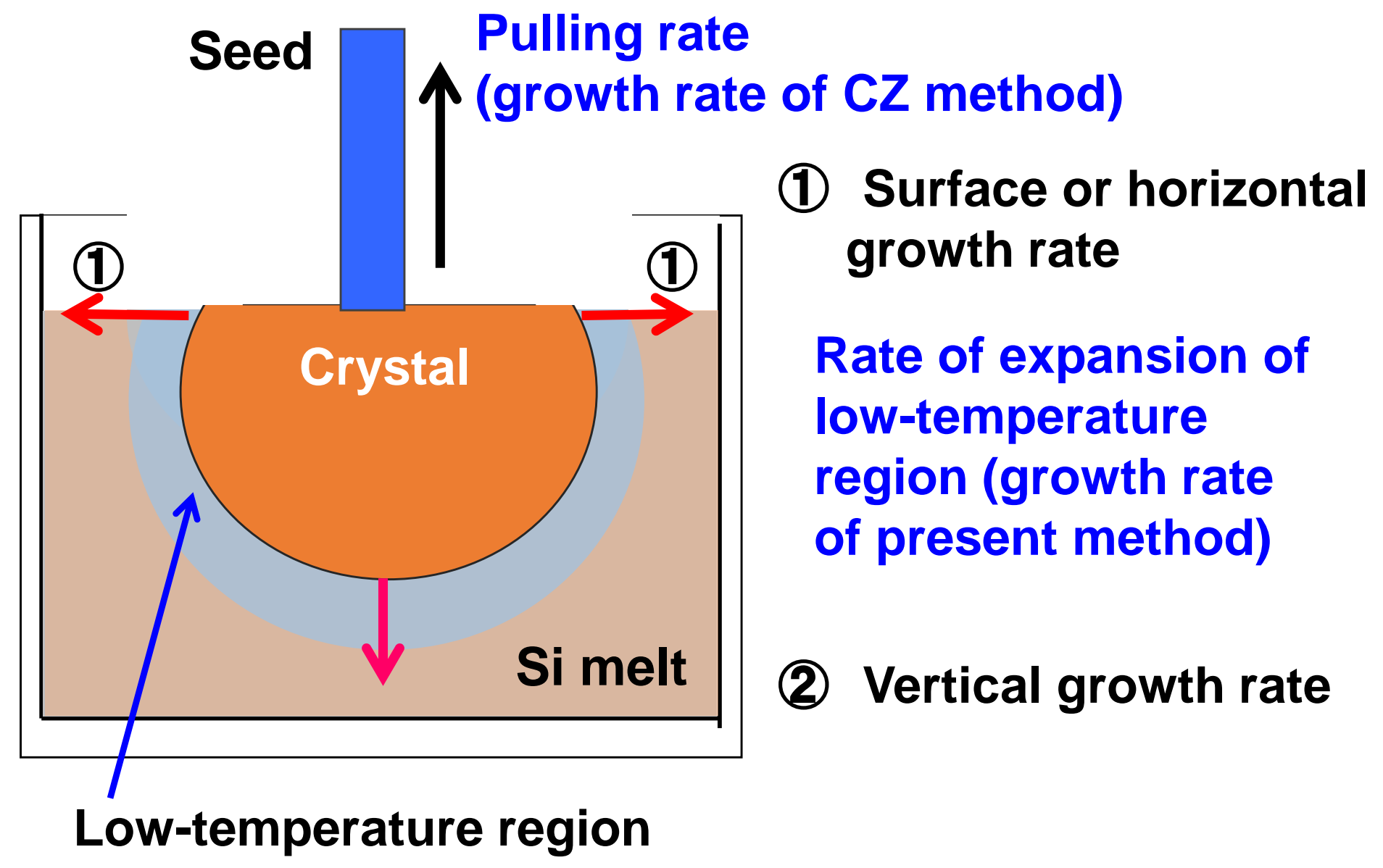

Fig. 1 K. Nakajima 

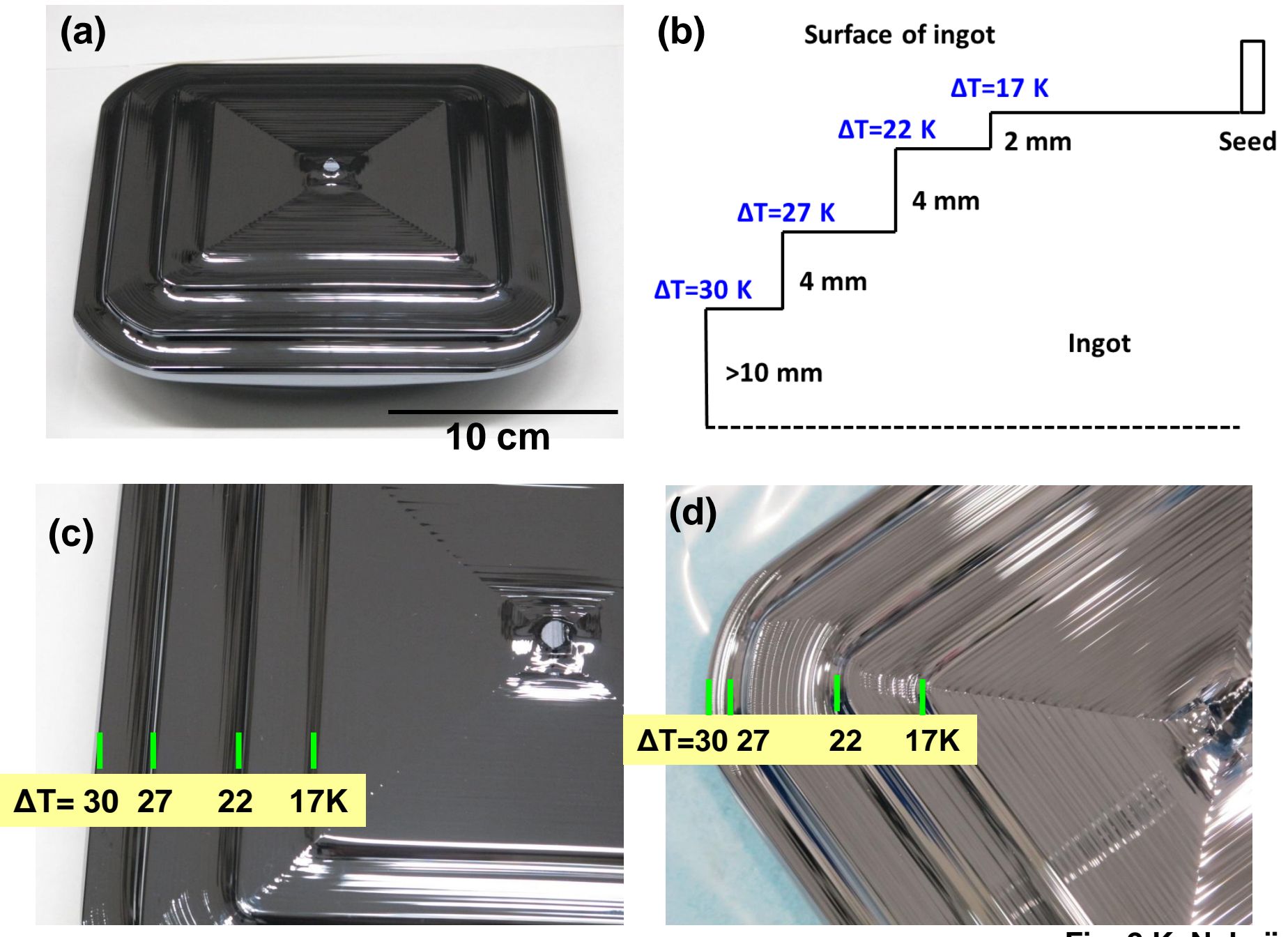

Fig. 2 K. Nakajima 
Surface growth rate

$0: 0.6 \mathrm{~mm} / \mathrm{min}$

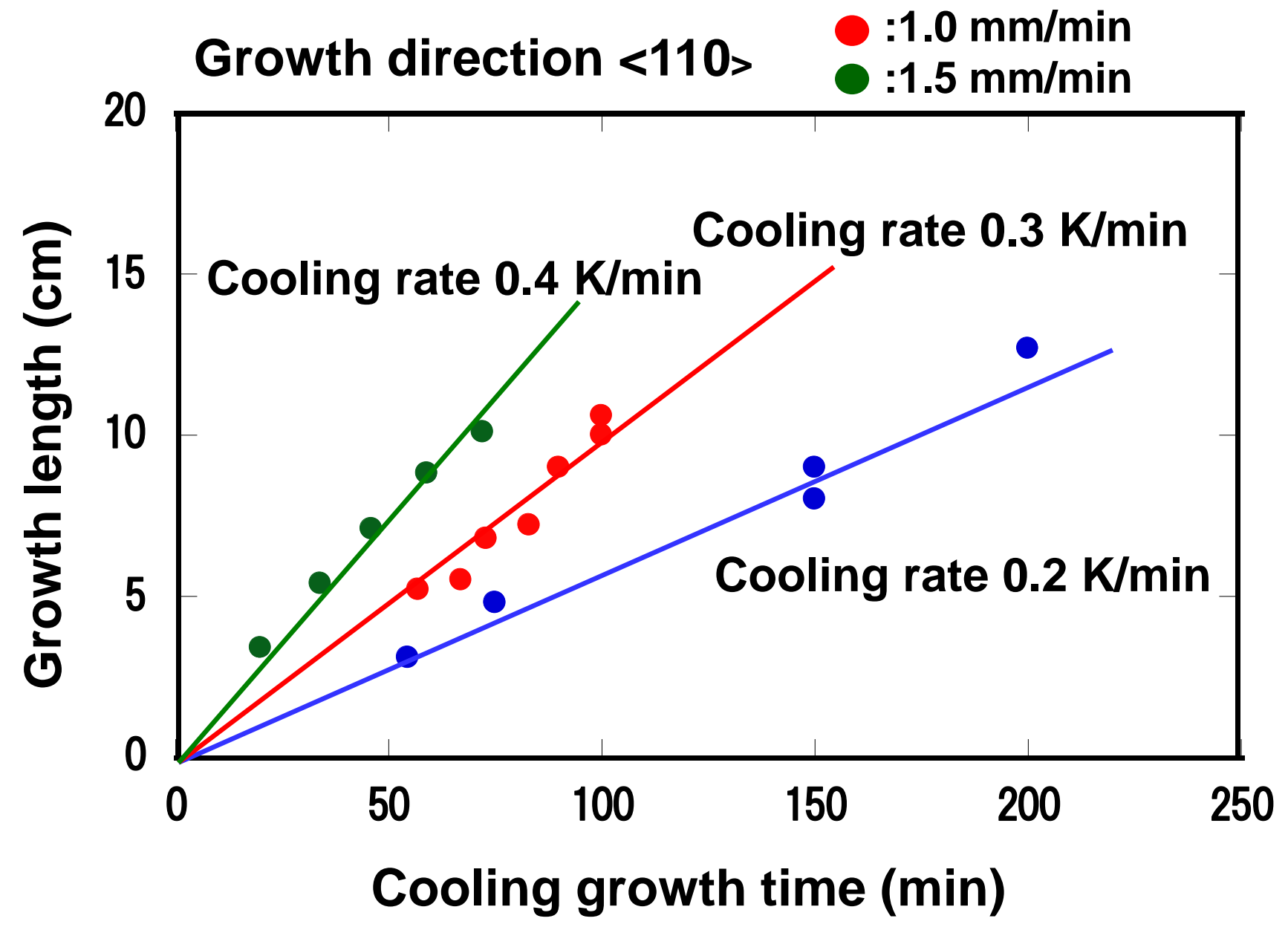

Fig. 3 K. Nakajima 
Surface growth rate

$0: 0.8 \mathrm{~mm} / \mathrm{min}$

Growth direction <100>

: $1.3 \mathrm{~mm} / \mathrm{min}$

$0: 1.9 \mathrm{~mm} / \mathrm{min}$

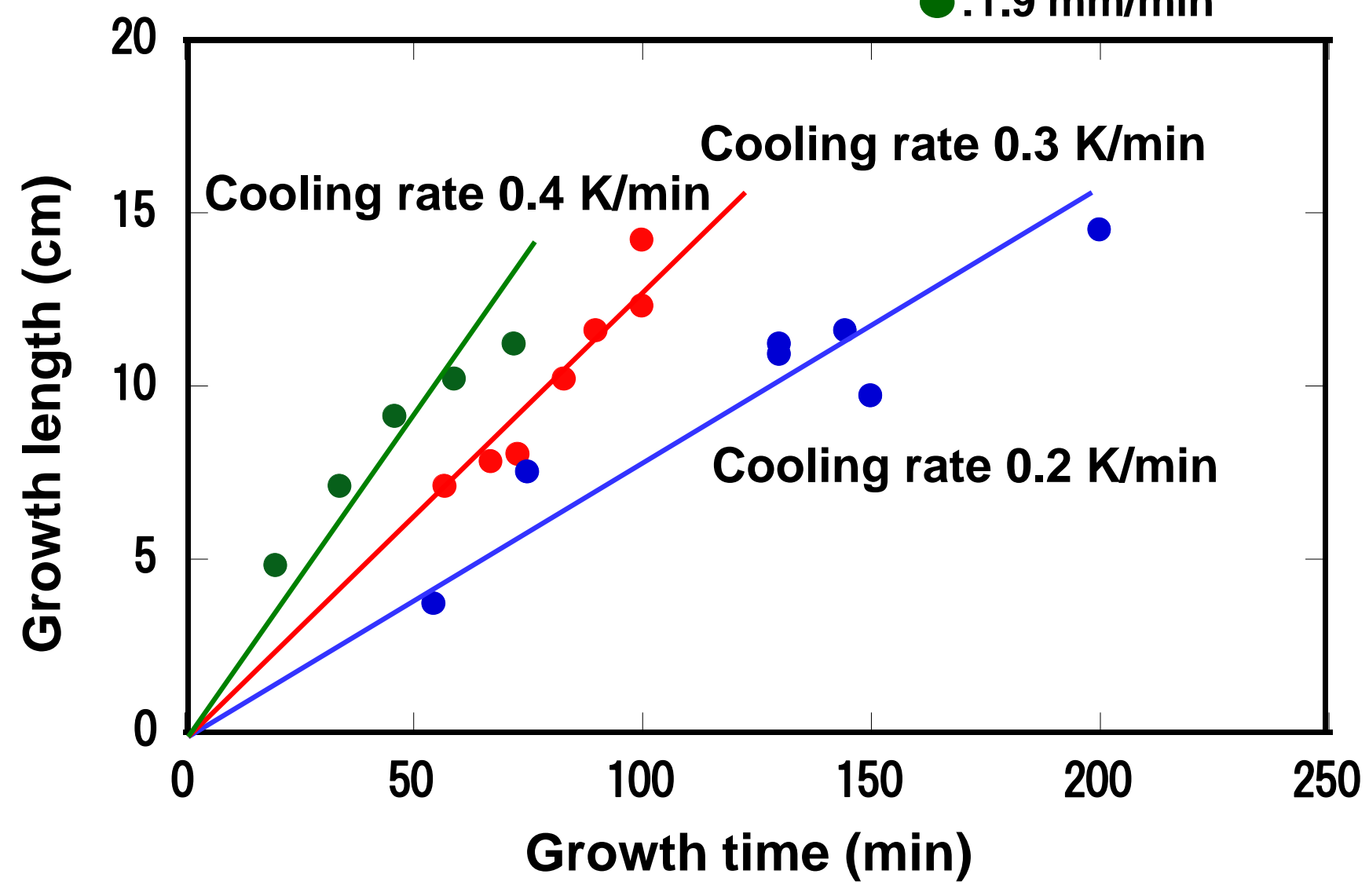

Fig. 4 K. Nakajima 


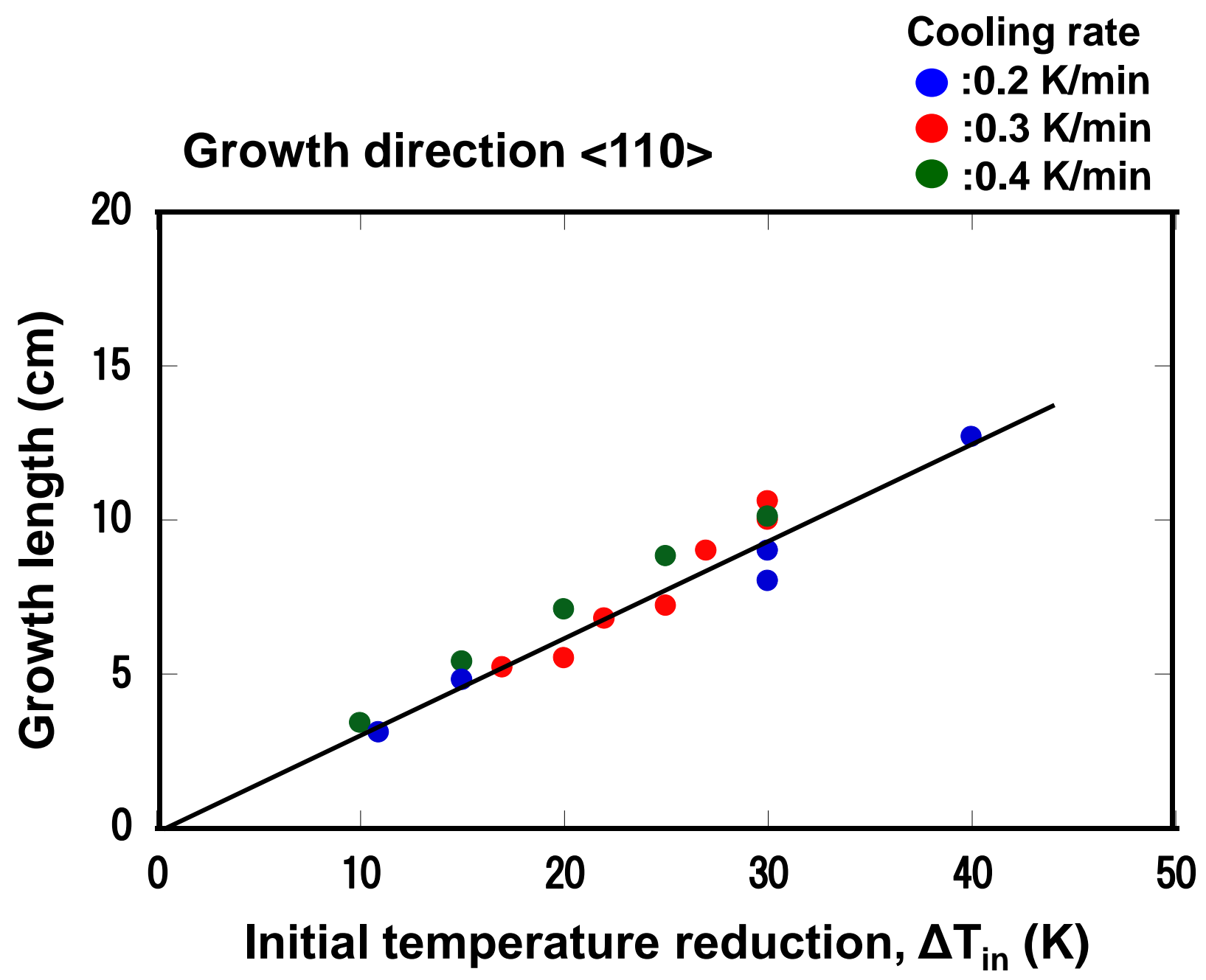

Fig. 5 K. Nakajima 
Cooling rate: $0.2 \mathrm{~K} / \mathrm{min}$

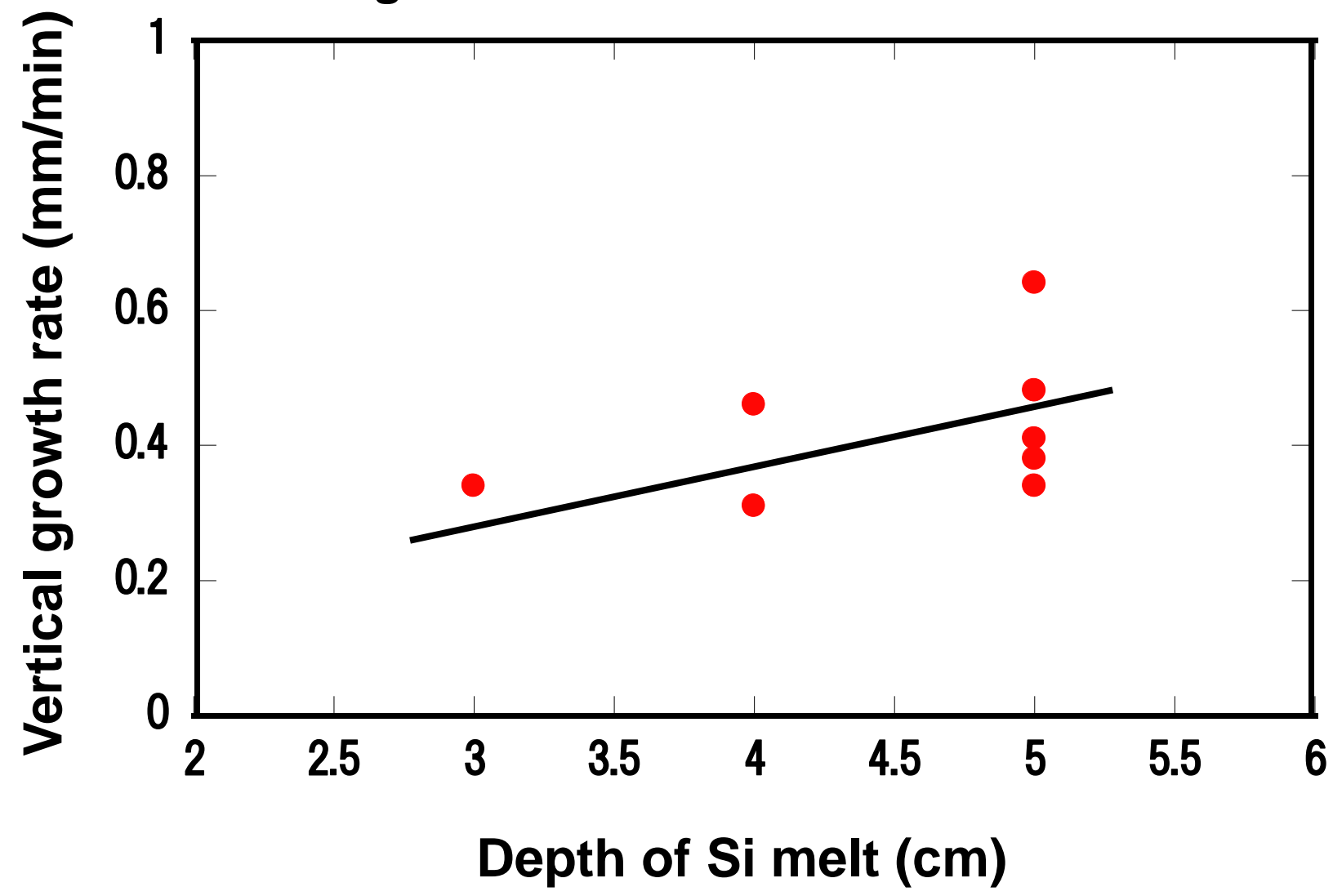

Fig. 6 K. Nakajima 
(a)

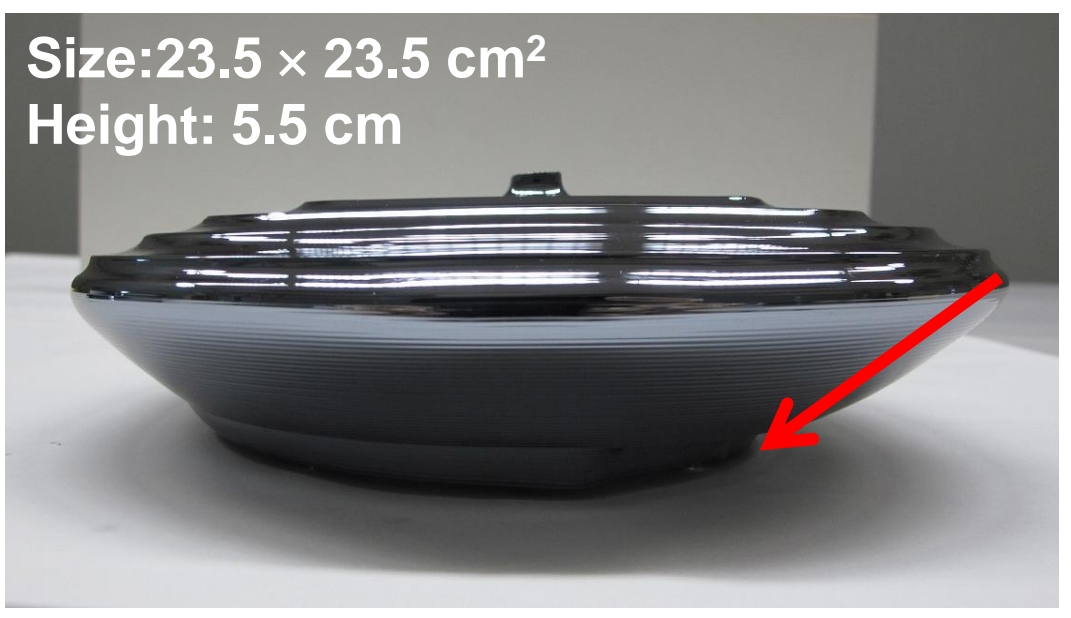

(c)

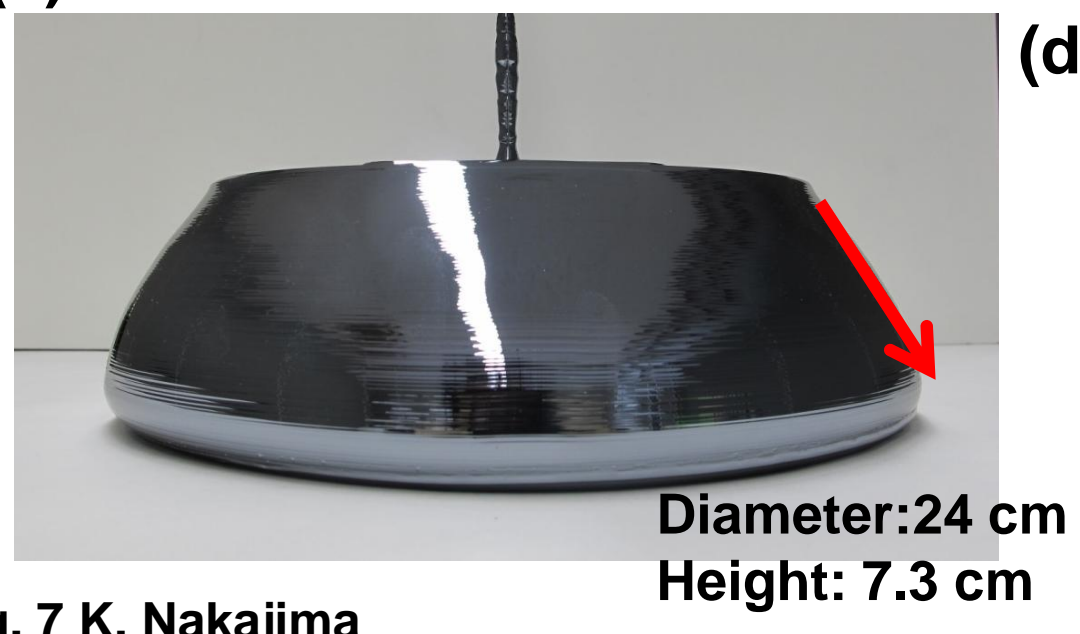

Square: $15.6 \times 15.6 \mathrm{~cm}^{2}$

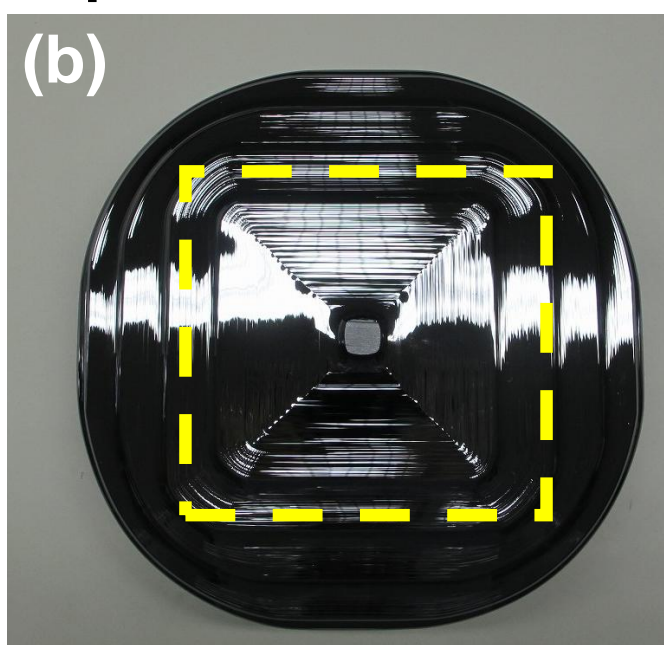

(d)

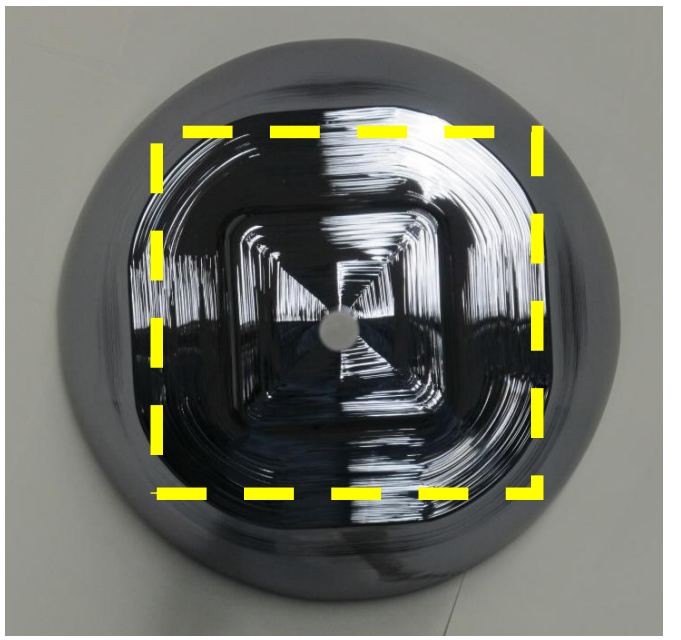

Fig. 7 K. Nakajima 

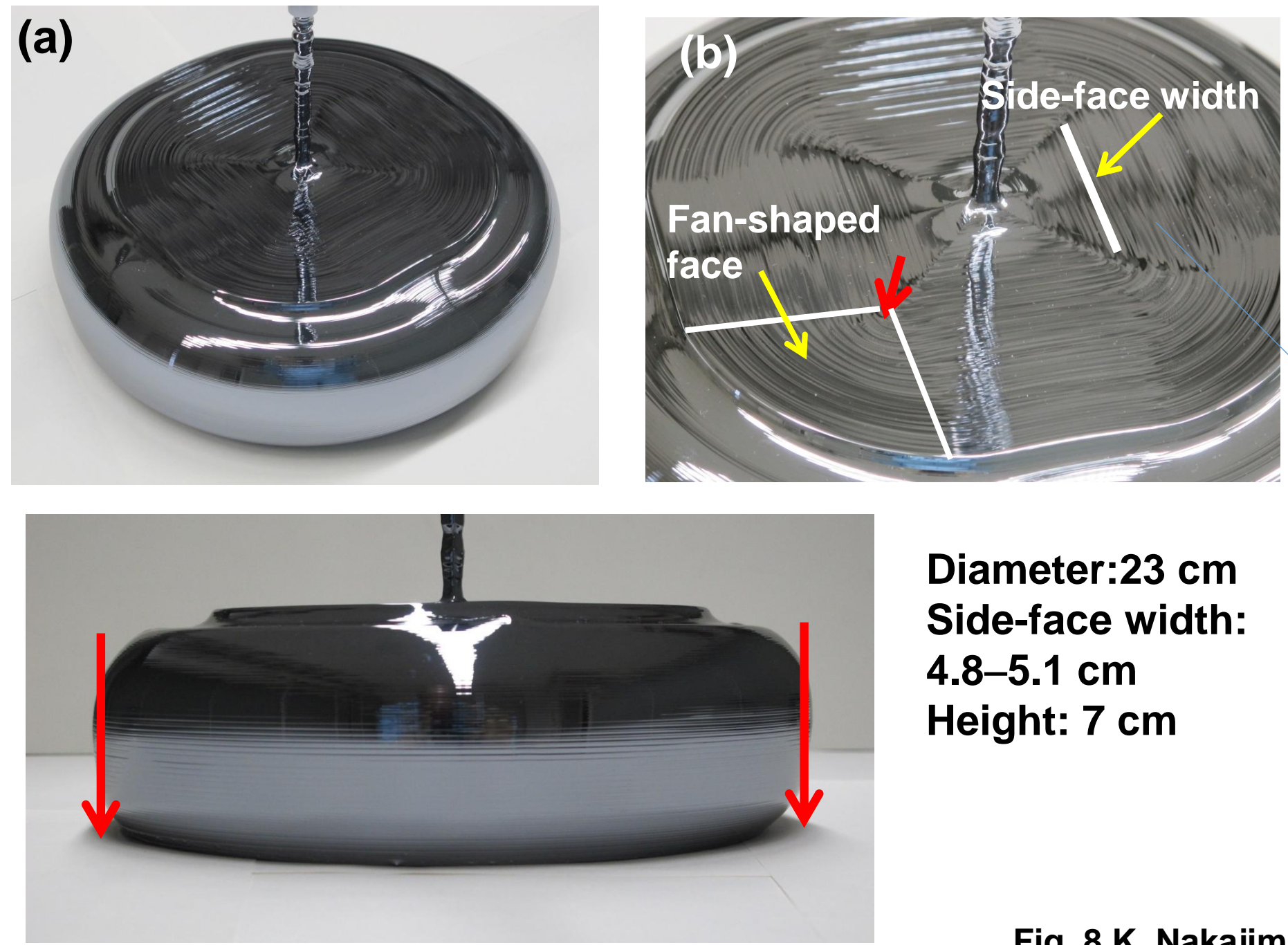

Diameter: $23 \mathrm{~cm}$ Side-face width: $4.8-5.1 \mathrm{~cm}$ Height: $7 \mathrm{~cm}$

Fig. 8 K. Nakajima 
Surface growth rate 0 : (a) $0.6 \mathrm{~mm} / \mathrm{min}$

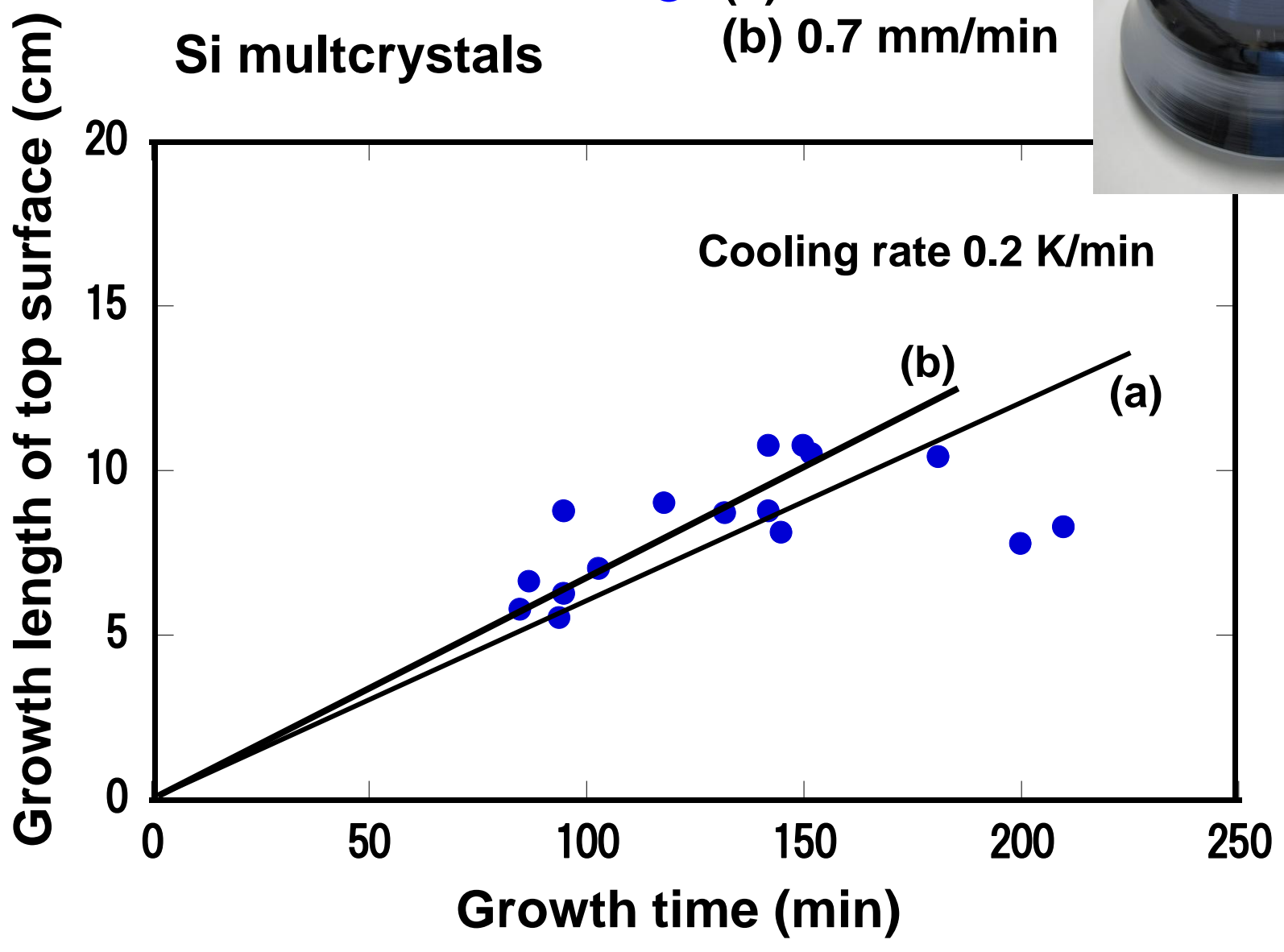

Fig. 9 K. Nakajima 


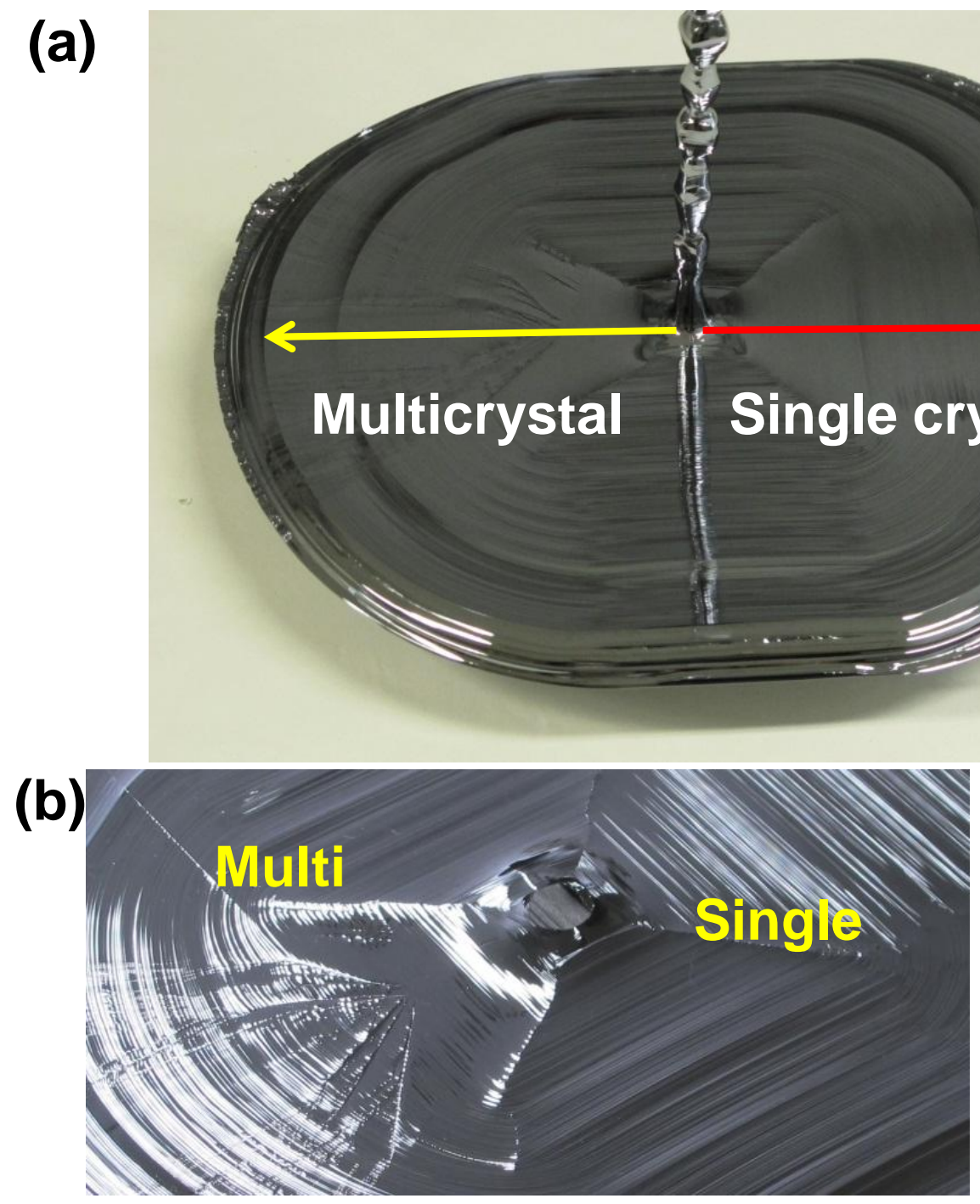

Surface growth rate Multicrystal : $0.8 \mathrm{~mm} / \mathrm{min}$ Single crystal: $0.7 \mathrm{~mm} / \mathrm{min}$

Fig. 10 K. Nakajima 